\title{
Differential Oxidative Stress Responses to D-Galactosamine- Lipopolysaccharide Hepatotoxicity Based on Real Time PCR Analysis of Selected Oxidant/Antioxidant and Apoptotic Gene Expressions in Rat
}

\author{
N. LEKIĆ ${ }^{1}$, D. ČERNÝ ${ }^{1}$, A. HOŘÍNEK ${ }^{2}$, Z. PROVAZNÍK ${ }^{3}$, J. MARTÍNEK $^{3}$, \\ H. FARGHALI ${ }^{1}$
}

${ }^{1}$ Institute of Pharmacology, First Faculty of Medicine, ${ }^{2}$ Institute of Biology and Human Genetics, First Faculty of Medicine, ${ }^{3}$ Institute of Histology and Embryology, First Faculty of Medicine, Charles University in Prague, Prague, Czech Republic

Received June 7, 2010

Accepted December 10, 2010

On-line March 14, 2011

\begin{abstract}
Summary
Oxidative stress and apoptosis are proposed mechanisms of cellular injury in studies of xenobiotic hepatotoxicity. This study is focused on addressing the mutual relationship and early signals of these mechanisms in the D-galactosamine and lipopolysaccharide (D-GaIN/LPS) hepatotoxicity model, with the help of standard liver function and biochemistry tests, histology, and measurement of gene expression by RT-PCR. Intraperitoneal injection of $400 \mathrm{mg} / \mathrm{kg} \mathrm{D-GalN}$ and $50 \mu \mathrm{g} / \mathrm{kg}$ LPS was able to induce hepatotoxicity in rats, as evidenced by significant increases in liver enzymes (ALT, AST) and raised bilirubin levels in plasma. Heme oxygenase- 1 and nitric oxide synthase- 2 gene expressions were significantly increased, along with levels of their products, bilirubin and nitrite. The gene expression of glutathione peroxidase 1 remained unchanged, whereas a decrease in superoxide dismutase 1 gene expression was noted. Furthermore, the significant increase in the gene expression of apoptotic genes Bid, Bax and caspase-3 indicate early activation of apoptotic pathways, which was confirmed by histological evaluation. In contrast, the measured caspase-3 activity remained unchanged. Overall, the results have revealed differential oxidative stress and apoptotic responses, which deserves further investigations in this hepatotoxicity model.
\end{abstract}

\section{Key words}

Hepatotoxicity $\bullet$ D-galactosamine/Lipopolysaccharide $\bullet$ Apoptosis

- Oxidative stress • RT-PCR

\section{Corresponding author}

Nataša Lekić, Institute of Pharmacology, $1^{\text {st }}$ Faculty of Medicine, Charles University, Albertov 4, 12800 Prague 2, Czech Republic. E-mail: nalekic@hotmail.com

\section{Introduction}

Liver is vulnerable to cellular damage, due to its extensive exposure to high concentrations of xenobiotics. Fulminant hepatic failure (FHF) can be induced by viral infection or xenobiotic injury and its incidence in population is low: however, unless a liver transplantation is carried out the rates of mortality are high (Chan et al. 2009). Combination of D-galactosamine and lipopolysaccharide (D-GalN/LPS) is a well established experimental model for studies of FHF (Feng et al. 2007, Silverstein 2004). Administration of D-GalN/LPS causes cytokine release that contributes to increased oxidative stress and formation of reactive oxygen species, which are fatal to the cell and result in hepatocyte death (Liu et al. 2008, Oberholzer et al. 2001). In addition, D-GalN inhibits mRNA and protein synthesis as it depletes the uridine triphosphate pool (Stachlewitz et al. 1999). The exact mechanism of cellular damage in FHF remains unclear. Identifying novel and sensitive early markers in this model of hepatotoxicity that can be used to complement conventional liver function tests is still needed.

Furthermore, the oxidative stress causes a 
misbalance in pro-oxidant/antioxidant steady state due to generation of increased amount of oxidants resulting in cellular damage as manifested by apoptosis and/or necrosis (Hong et al. 2009). Oxidative stress can be induced by toxins and it causes accumulation of reactive oxygen/nitrogen species, by activation of inducible nitric oxide synthase (NOS-2) (Diesen and Kuo 2010). Heme oxygenase-1 (HO-1), superoxide dismutase 1 (SOD1), glutathione peroxidase $1(\mathrm{Gpx} 1)$ and catalase are major antioxidant enzymes, which along with the reactions that they catalyze, play important roles in defense against oxidative stress induced by toxins (Farombi and Surh 2006, Mari et al. 2009, Valdivia et al. 2009). Oxidative stress can induce a TNF- $\alpha$ mediated apoptosis that involves the activation of executive caspases and the members of Bcl-2 family proteins BH3 interacting domain death agonist (Bid) and Bcl-2-associated X protein (Bax) (Morgan et al. 2010, Van Herreweghe et al. 2010). Clarifying the steps involved in the complex interaction between the oxidative stress and apoptotic mechanisms is of great value in identifying early markers of cell injury.

One of the approaches to methods in toxicity research that has gained popularity in recent decades is study of toxicogenomics, which focuses on gene and protein activity responses to toxic substances (Gatzidou et al. 2007). Real time PCR analysis is one of the methods that has been proven reliable in verification of gene expressions in this field. As well, this method in combination with histopathology and biochemistry provides a further mechanistic approach to research in toxicology (Harril and Rusyn 2008). Our previous research work addressed the mutual cross talk of $\mathrm{CO} / \mathrm{HO}-1$ and NO/NOS-2 systems in the D-galactosamine (D-GalN)/lipopolysaccharide (LPS) hepatotoxicity (Farghali et al. 2009) with the use of these three before mentioned methods. The aim of this study is to provide further insight into the mechanisms of cellular injury in this model, by focusing on involvement of several other major antioxidant enzymes and apoptotic mediators. By analysis of their gene expressions we will attempt to address potential early signals of cell injury and existence of a relationship between conventional liver dysfunction markers and the select gene expression responses.

\section{Materials and Methods}

\section{Animals and experimental design}

This study was performed on male Wistar rats of
200-300 g body weight obtained from Velaz-Lysolaje, Czech Republic. They were given water and standard granulated diet ad libitum and were maintained under standard conditions; light (i.e. $12 \mathrm{~h}$ light and $12 \mathrm{~h}$ dark); temperature $\left(22 \pm 2{ }^{\circ} \mathrm{C}\right)$; relative humidity $(50 \pm 10 \%)$. All rats received humane care according to the general guidelines and approval of the Ethical Committee of the First Faculty of Medicine, Charles University in Prague. Rats in the D-GalN/LPS group were injected intraperitoneally with a dose of $400 \mathrm{mg} / \mathrm{kg}$ D-GalN (D-galactosamine hydrochloride) and $50 \mu \mathrm{g} / \mathrm{kg}$ LPS (lipopolysaccharide from Escherichia coli K-235) dissolved in dimethyl sulfoxide (DMSO), the control group received the equal volume of vehicle only. Eight animals of each group were killed at twenty four hours after injection under light ether anasthesia, after which the blood samples were collected. Following this, livers were excised quickly and perfused for morphological evaluation, preserved in liquid nitrogen for RT-PCR studies, and homogenized for biochemical study.

\section{Measurements of liver enzymes and bilirubin}

Determination of plasma alanine aminotransferase (ALT) was carried out using Fluitest ${ }^{\circledR}$

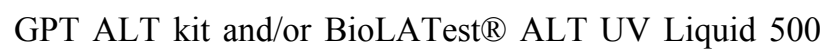
tests. Fluitest ${ }^{\circledR}$ GOT AST kit by Analyticon and/or BioLATest ${ }^{\circledR}$ AST UV Liquid 500 tests were used in determination of aspartate aminotransferase (AST) plasma levels. Total bilirubin in plasma was measured using Fluitest ${ }^{\circledR}$ BIL-Total kit.

Determination of $\mathrm{NO}_{2}^{-} / \mathrm{NO}_{3}^{-}$, reduced glutathione (GSH) and catalase levels

Assessment of plasma $\mathrm{NO}_{2}{ }^{-} / \mathrm{NO}_{3}{ }^{-}$was carried out using a nitrate/nitrite colourimetric assay kit of Cayman Chemical Company (An Arbor, MI) and a microplate reader according to manufacturer's instructions. In short, this method is based on a colourimetric conversion of nitrate $\left(\mathrm{NO}_{3}{ }^{-}\right)$to nitrite $\left(\mathrm{NO}_{2}{ }^{-}\right)$by nitrate reductase. The addition of the Griess reagent $(1 \%$ sulfanilamide, $0.1 \%$ naphtylethylendiamine, $2.5 \% \mathrm{H}_{3} \mathrm{PO}_{4}$ ) converts nitrite into a coloured azo compound. Spectrophotometrical measurement of absorbance at $540 \mathrm{~nm}$ determines the nitrite concentration, using the appropriate standard curve. Assessment of reduced gluathione in homogenate was based on the method that depends on a reaction between thiol group with 5,5-dithio-2-nitrobenzoic acid (DTNB) which can be measured spectrophotometrically (Sedlak 
and Lindsay 1968). The measurement of catalase in plasma was performed according to the reaction between $\mathrm{H}_{2} \mathrm{O}_{2}$ and molybdenium ammonium as previously reported (Aebi 1984).

Lipid peroxidation: the thiobarbituric acid reacting substances (TBARS) and conjugated dienes (CD) measurement

D-GalN/LPS lipid peroxidation of the rat liver was assayed by the thiobarbituric acid (TBARS) method, and the spectrofluorometric assay for conjugated dienes (CD) was carried out as described earlier (Yokode et al. 1988). The results were expressed in $\mathrm{nmol} / \mathrm{mg}$ of total protein.

Select gene expression measurements with the use of real-time PCR method

Twenty-four hours following drug administration, the liver samples were obtained to be used for total RNA isolation according to the manufacturer's instructions of the Qiagen ${ }^{\circledR}$ RNeasy plus kit (Bio-Consult Laboratories). Following total RNA isolation, the reverse transcription from total RNA to cDNA was processed by universal kit GeneAmp® RNA PCR using a murine leukemia virus $(\mathrm{MuLv})$ reverse trancriptase (RT). Reverse transcription included the following three phases: $10 \mathrm{~min}$ at $25{ }^{\circ} \mathrm{C}$ for RT enzyme activation, $30 \mathrm{~min}$ at $48{ }^{\circ} \mathrm{C}$ for $\mathrm{PCR}$ amplification and $5 \mathrm{~min}$ at $95^{\circ} \mathrm{C}$ for denaturation.

Expressions of select genes were evaluated using real-time polymerase chain reaction (RT-PCR) of cDNA originating from total RNA, with the help of ABI PRISM 7900, and TagMan ${ }^{\circledR}$ Gene Expression master mix (Applied Biosystems). Total of eight genes were evaluated using the TagMan ${ }^{\circledR}$ Gene Expression Assays Kit - nitric oxide synthase-2 (NOS-2), heme oxygenase-1 (HO-1), glutathione peroxidase 1 (Gpx1), superoxide dismutase 1 (SOD1), BH3 interacting domain death agonist (Bid), Bcl-2 -associated $\mathrm{X}$ protein (Bax), caspase 3 (Casp 3) - as genes of interest (target genes) and glyceraldehyde 3-phosphate dehydrogenase (Gapdh) gene as a control (endogenous or housekeeping) gene, using the FAM coloured primes and probes. Housekeeping gene-expression was stable and constant during the experiment and was used in comparison with target geneexpression. Thermal cycling conditions for primer and probes optimization were $10 \mathrm{~min}$ at $90-95^{\circ} \mathrm{C}$ for Taq polymerase activation, followed by $15 \mathrm{~s}$ at $95-99{ }^{\circ} \mathrm{C}$ for DNA denaturation and $1 \mathrm{~min}$ at $60^{\circ} \mathrm{C}$ for annealing. The obtained $\mathrm{Ct}$ values were used in relative quantification of gene expression measurements relative to the endogenous gene control $\mathrm{Ct}$ measurements, and the relative gene expression was calculated using the $\Delta \Delta \mathrm{Ct}$ method. (Arocho et al. 2006).

Measurement of caspase 3 activity and morphological evaluation

Cell lysates were prepared according to the instructions of Sigma-Aldrich (Prague, Czech Republic) fluorometric caspase 3 assay kit. The results were expressed as percentage of caspase 3 activity in the treated group relative to the control. The protein concentration in the supernatant was determined using an Bio-Rad protein assay kit according to the manufacturer's instructions.

Morphological evaluation of hepatocytes at the light microscopical level was done on semithin epon sections (1-2 $\mu \mathrm{m}$ thick) stained by toluidine blue using Leica IM 500 program for digital recording and measurements.

\section{Statistical examinations}

All experiments were performed in two groups of eight rats with the reported results stated as \pm standard error of mean. The statistical analysis was performed using unpaired T-test with Welch correction. The p-values less than 0.05 were considered significant.

\section{Results}

Effects of D-GalN/LPS treatment on liver function, lipid peroxidation and oxidative stress parameters

The combination D-GalN/LPS treatment in rats has produced hepatic failure, which can be seen by highly significant $(\mathrm{p}<0.001)$ increases in levels of aminotransferases in plasma. A two hundred fold increase in AST level and one hundred fold increase in ALT level compared to those of the control group was observed (Table 1). The extent of lipid peroxidation as measured by formation of thiobarbituric acid reactive substances (TBARS) and conjugated dienes (CD) did not show any statistically significant differences between the two groups $(p>0.05)$. Furthermore, Table 1 shows highly significant $(p<0.001)$ increase in antioxidant enzyme catalase (CAT) in plasma of D-GalN/LPS treated rats compared to control: however, there was no measurable change in its level in homogenate (data not shown). There was no significant $(\mathrm{p}>0.05)$ difference between the two groups in the measurement of reduced glutathione (GSH) level in homogenate. 
Table 1. Effects of lipopolysaccharide-induced hepatitis in D-galactosamine sensitized rats (D-GalN/LPS) on levels of alanine aminotransferase (ALT), aspartate aminotransferase (AST), catalase (CAT), conjugated dienes (CD), reduced glutathione (GSH) and formation of thiobarbituric acid reactive substances (TBARS) $24 \mathrm{~h}$ after injection.

\section{CONTROL D-GalN/LPS}

\begin{tabular}{lcc}
\hline ALT & & \\
Plasma & $0.8225 \pm 0.05$ & $166.948 \pm 12.42 * * *$ \\
AST & $2.016 \pm 0.09$ & $254.802 \pm 4.85 * * *$ \\
Plasma & & $156.00 \pm 1.88 * * *$ \\
CAT & $51.24 \pm 6.55$ & \\
Plasma & $2.45 \pm 0.57$ & $2.94 \pm 0.54 * \mathrm{~ns}^{*}$ \\
CD & & \\
Homogenate & & \\
GSH & $458.36 \pm 19.06 \pm 49.89 * \mathrm{~ns} *$ \\
Homogenate & & $261.12 \pm 6.10 * \mathrm{~ns} *$ \\
TBARS & $197.84 \pm 22.24$ & \\
Homogenate &
\end{tabular}

CONTROL: negative control group receiving vehicle only. D-GalN/LPS: D-galactosamine $400 \mathrm{mg} / \mathrm{kg}$ with lipopolysaccharide $50 \mu \mathrm{g} / \mathrm{kg}$; Units: ALT and AST $\mu \mathrm{cat} / \mathrm{l} ; \mathrm{CAT}-\mu \mathrm{mol} / \mathrm{ml} ; \mathrm{CD}$ and TBARS- $\mathrm{nmol} / \mathrm{mg}$ protein; GSH- $\mu \mathrm{mol} / \mathrm{mg}$ protein; Values are mean $\pm \mathrm{S} . \mathrm{E} . \mathrm{M} ., \mathrm{n}=8$; $*_{n} *$ non-significant value compared to the negative control group (CONTROL) $\mathrm{p}>0.05 ; *, * *, * * *$ value significant compared to CONTROL $p \leq 0.05^{*}, p \leq 0.01 * *, p \leq 0.001 * * *$.

Fig. 1 further demonstrates changes in the gene expression of selected antioxidant enzymes as measured by the RT-PCR method. Glutathione peroxidase 1 (Gpx1) and superoxide dismutase 1 (SOD1) gene expressions were related to Gadph as the endogenous control, and measured in both D-GalN/LPS and the control groups. The increase of Gpx1 gene expression in the treated group is non significant ( $\mathrm{p}>0.05$ ); however, D-GalN/LPS treatment has caused a highly significant decrease of SOD1 gene expression in comparison to the untreated control group.

The extent of heme catabolism as shown in the Fig. 2a, illustrates significantly higher levels of bilirubin in plasma of D-GalN/LPS treated rats compared to that of the control group. The same trend is observed in the inducible HO-1 gene expression (Fig. 2b) relative to the Gapdh, where the seven fold increase in the D-GalN/LPS treated group is highly significant. In comparison to the untreated control animals, D-GalN/LPS treatment induced simultaneous statistically significant increase in both plasma $\mathrm{NO}_{2}^{-}$levels (Fig. 3a) and NOS-2 expression relative to Gapdh as endogeneous control (Fig. 3b).

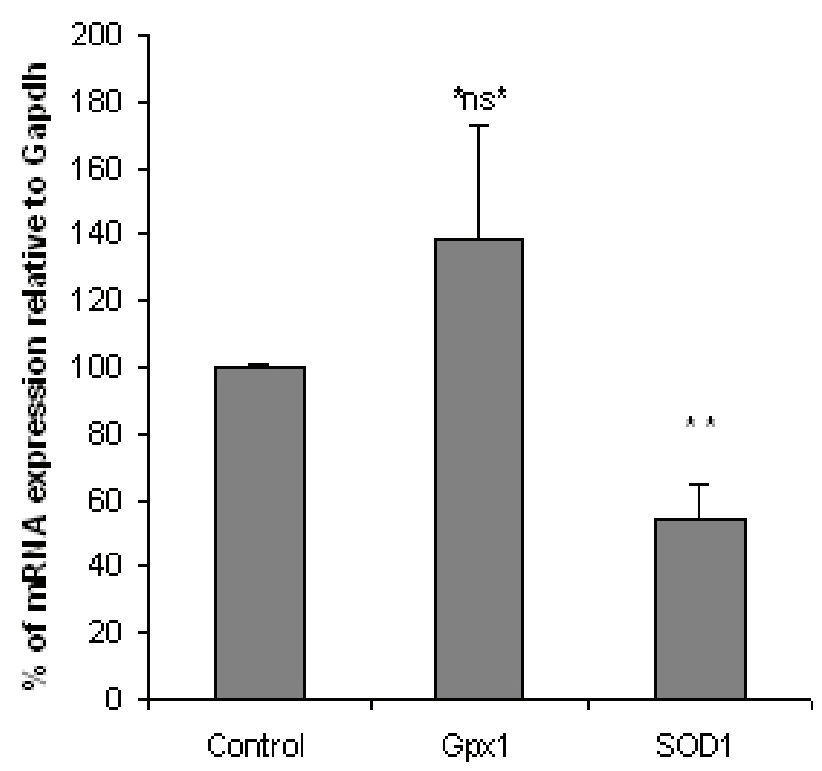

Fig. 1. Effect of lipopolysaccharide-induced hepatitis in D-galactosamine sensitized rats (D-GalN/LPS) on Gpx1 and SOD1 gene expressions relative to Gapdh as the endogenous control $24 \mathrm{~h}$ after injection. Control: vehicle only; D-GalN/LPS: D-galactosamine $400 \mathrm{mg} / \mathrm{kg}$ with lipopolysaccharide $50 \mu \mathrm{g} / \mathrm{kg}$; Values are mean \pm S.E.M., $n=8 ;{ }^{*} n s^{*}$ non-significant value compared to the negative control group (Control) p $>0.05$; ** value significant compared to Control $p \leq 0.01 * *$. 
a

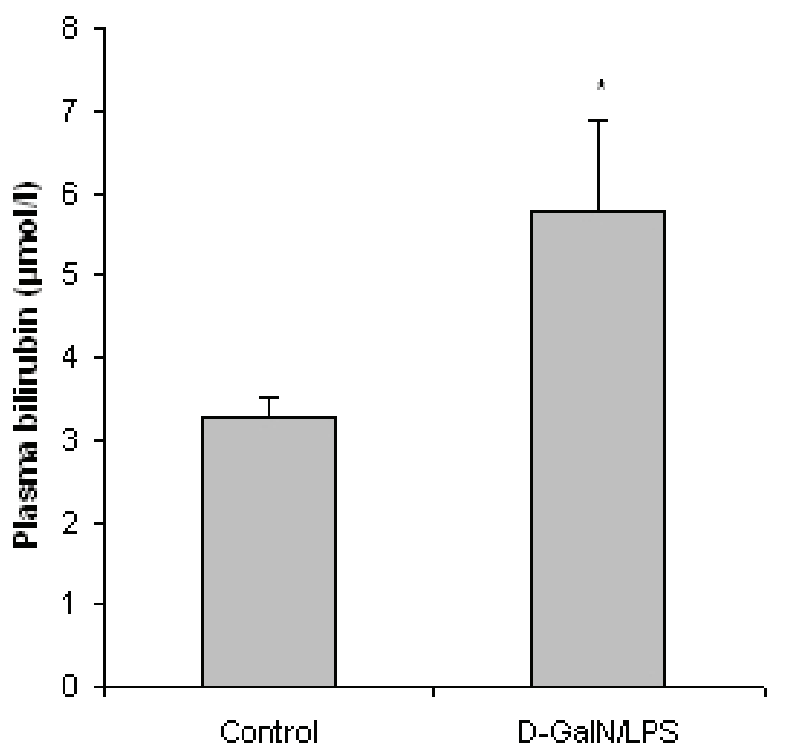

b

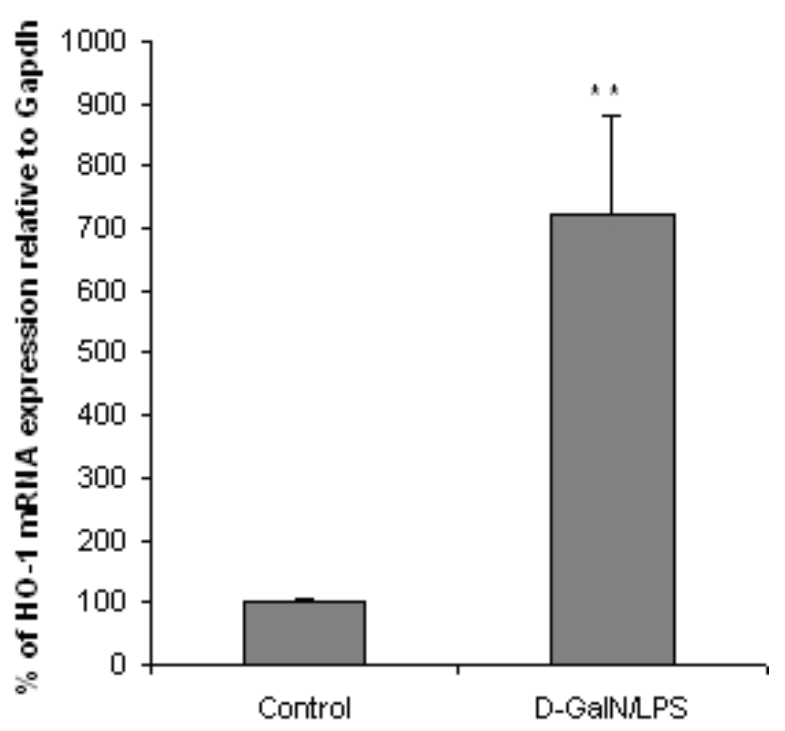

Fig. 2. Effect of lipopolysaccharide-induced hepatitis in D-galactosamine sensitized rats (D-GalN/LPS) on plasma bilirubin (a) and on HO-1 gene expression relative to Gapdh as the endogenous control (b) $24 \mathrm{~h}$ after injection. Control: vehicle only; D-GalN/LPS: D-galactosamine $400 \mathrm{mg} / \mathrm{kg}$ with lipopolysaccharide $50 \mu \mathrm{g} / \mathrm{kg}$; Values are mean \pm S.E.M., $\mathrm{n}=8$; $*, * *$ value significant compared to Control $p \leq 0.05^{*}, p \leq 0.01^{* *}$.

Effects of D-GalN/LPS treatment on apoptotic markers and morphological findings

Measurements of selected apoptotic parameters are illustrated in the Fig. 4. Caspase 3 activity, although slightly increased in the D-GalN/LPS group, is not significantly different from the control group (Fig. 4a): however, the expression of Casp 3 gene did show a significant increase. The same trend is also observed in the expressions of Bid and Bax genes, where the increase a

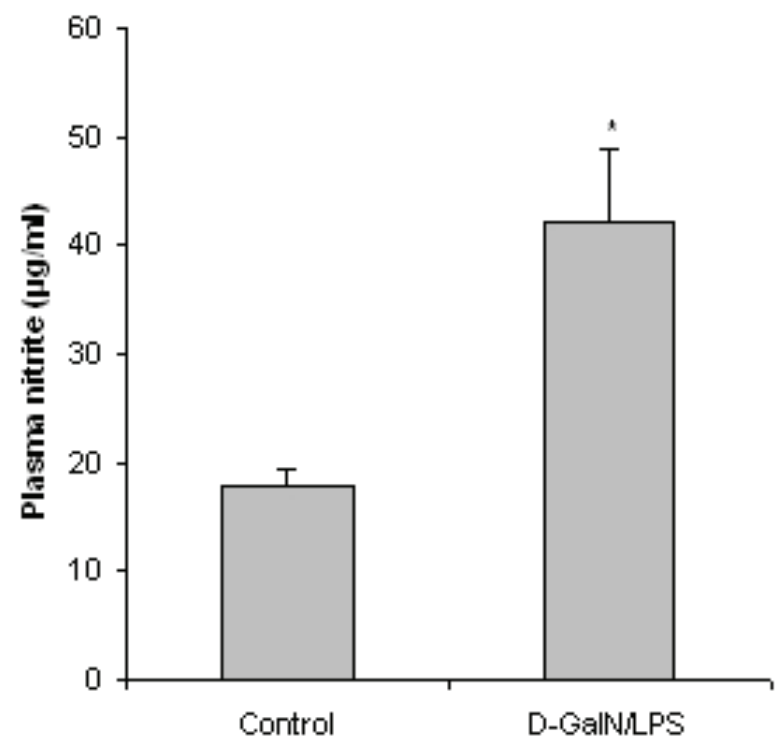

b



Fig. 3. Effect of lipopolysaccharide-induced hepatitis in D-galactosamine sensitized rats (D-GalN/LPS) on plasma $\mathrm{NO}_{2}{ }^{-}$ (a) and on NOS-2 gene expression relative to Gapdh as the endogenous control (b) $24 \mathrm{~h}$ after injection. Control: vehicle only; D-GalN/LPS: D-galactosamine $400 \mathrm{mg} / \mathrm{kg}$ with lipopolysaccharide $50 \mu \mathrm{g} / \mathrm{kg}$; Values are mean \pm S.E.M., $\mathrm{n}=8$; $*$ value significant compared to Control $p \leq 0.05 *$.

in the D-GalN/LPS treated group was statistically significant. Bax gene expression was more than two-fold and thus the highest of the three apoptotic genes that were measured.

The morphological evaluation has shown the well preserved cytological features of the control liver tissues. Specifically, the periphreal region of the central vein lobules consists of radially arranged cords of hepatocytes with more or less comparable cytological 


\section{a}

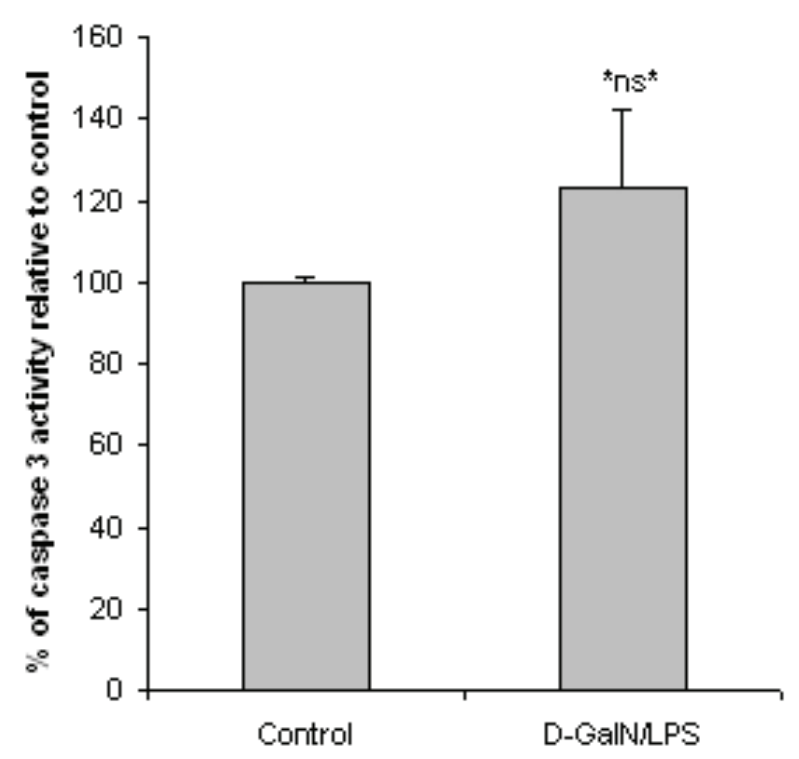

b

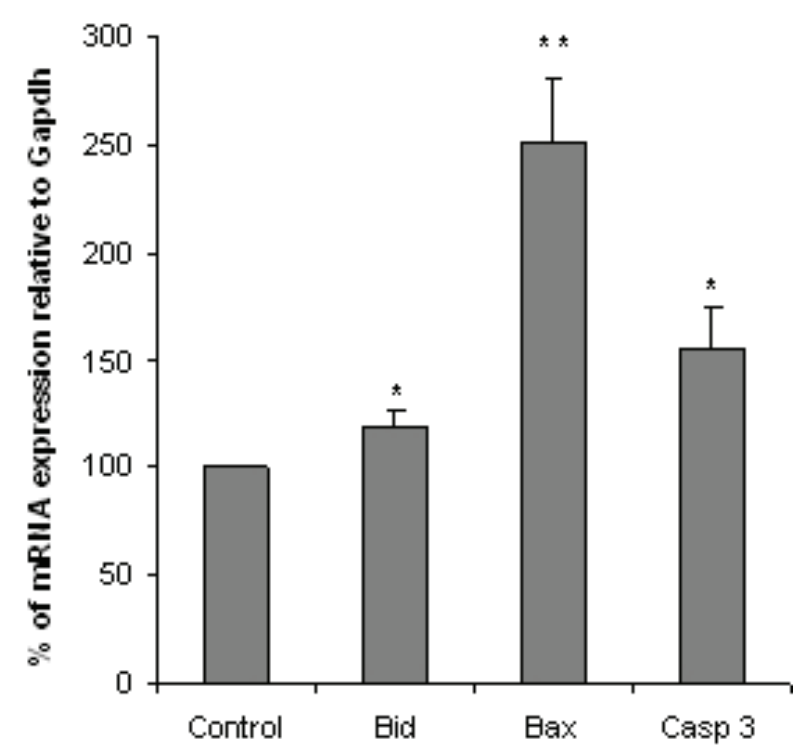

Fig. 4. Effect of lipopolysaccharide-induced hepatitis in D-galactosamine sensitized rats (D-GaIN/LPS) on Caspase 3 activity (a) and on Bid, Bax and Casp 3 gene expressions relative to Gapdh as the endogenous control (b) $24 \mathrm{~h}$ after injection. Control: vehicle only; D-GalN/LPS: D-galactosamine $400 \mathrm{mg} / \mathrm{kg}$ with lipopolysaccharide $50 \mu \mathrm{g} / \mathrm{kg}$; Values are mean \pm S.E.M., $\mathrm{n}=8$; *ns* non-significant value compared to the negative control group (Control) $\mathrm{p}>0.05 ; *, * *$ value significant compared to Control $\mathrm{p} \leq 0.05^{*}, \mathrm{p} \leq 0.01^{* *}$.

features, such as stainability of the cytoplasm and distribution of cell organelles (Fig. 5a). The administration of D-GalN/LPS has significantly affected morphological parameters of the rat livers. Even at the lower magnification (Fig. 5b) striking necrotic lesions can be observed in the peripheral and intermediate regions of the central vein lobules. Typical changes and aggregation of heterochromatin near the nuclear envelope confirm the occurence of apoptosis in some hepatocytes (Fig. 5c). At the peripheral region of some injured lobules transitional change of aponecrosis can be detected and the presence of pycnotic nuclei is clearly visible (Fig. 5d).

\section{Discussion}

Understanding the exact mechanism of xenobiotic hepatotoxicity is one of the major challenges hepatologists are faced with today. Recent advances in the studies of toxicogenomics have been useful in elucidating several different pathways of hepatotoxicity. Further research is needed to confirm these results as well to gain a mechanistic understanding of toxic changes that occur in the liver. As before mentioned, combination of D-GalN/LPS is a useful model for hepatotoxicity research that resembles fulminant hepatic failure. In this study, the administration of D-GalN/LPS significantly increased the levels of ALT and AST, which are indicative of failing liver function and are a cardinal feature in the FHF. The impairment of biliary function has been seen by the raised levels of bilirubin in the D-GalN/LPS treated animals. The present study revealed that the extent of lipid peroxidation in this model seems to be non significant, since the levels of conjugated dienes and the measured TBARS in plasma of D-GalN/LPS treated animals were not different from those of the control group.

Heme oxygenase-1 is the inducible isoform that is activated in response to cellular stress, playing a main role in degradation of heme into carbon monoxide, free iron and biliverdin. In turn, the enzyme biliverdin reductase converts biliverdin into bilirubin, a powerful antioxidant with cytoprotective capabilities that has been linked to increased heme oxygenase activity (Baranano et al. 2002, Clark et al. 2000). As well, the other heme degradation pathway products, biliverdin and carbon monoxide, play a protective role against oxidative stress which may explain the observed increase in HO-1 expression (Lehmann et al. 2010, Zhu et al. 2008). One of the ways lipopolysaccharide exerts its inflammatory action is by stimulation of production of pro-inflammatory cytokine TNF- $\alpha$ by the Kupffer cells. (Lichtman et al. 1994). The cooperative action of biliverdin/bilirubin and $\mathrm{CO}$ was reported to be responsible for the prolonged survival of mice in the D-GalN/LPS model of hepatotoxicity due to cytokine reduction, specifically TNF- $\alpha$ (Sass et al. 2004). This is relevant to the observed parallel increase in both HO-1 expression and bilirubin levels in this experiment. 


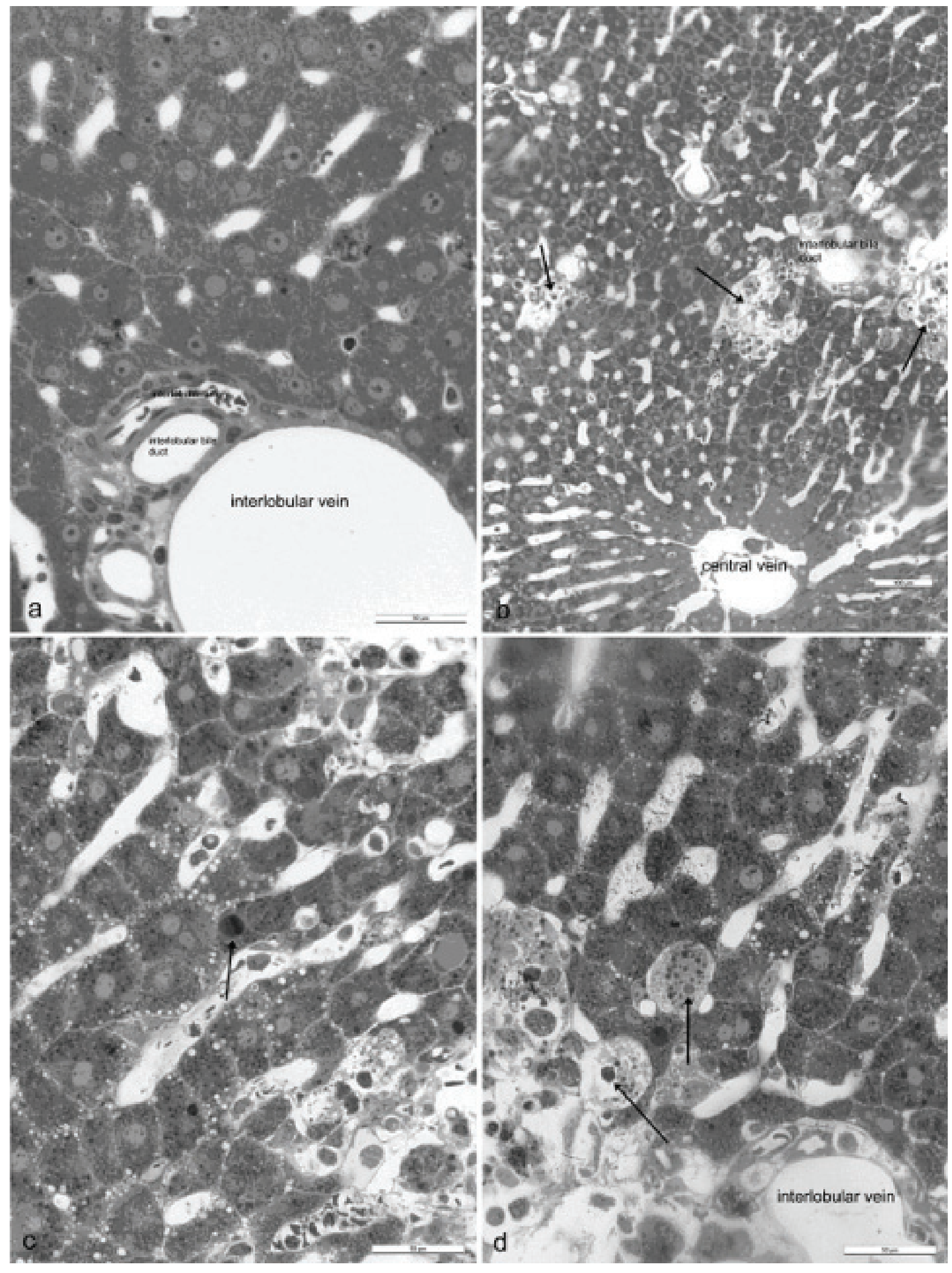

Fig. 5. Light microscopy morphological findings of rat liver of control and D-GaIN/LPS treated samples: a) control hepatocyte liverperipheral region of the central vein lobule; trabecular arrangement of polyhedral hepatocytes demonstrates well preserved cytological features; bar $50 \mu \mathrm{m}$. b) the effect of D-GalN/LPS treatment (low magnification) - striking necrotic lesions can be seen in the peripheral and intermediate (arrows) regions of a central vein lobule of the liver; many transparent pseudovacuoles are visible; bar $100 \mu \mathrm{m}$; c) the effect of D-GalN/LPS treatment (higher magnification) - increased number of neutral lipid droplets, increased distribution of dark granular accumulations in the cytoplasm and activated lysosomal apparatus of injured hepatocytes are seen; typical changes of demilunar apoptotic heterochromatin arrangement in the nucleus are indicated by an arrow; bar $50 \mu \mathrm{m}$; d) peripheral region of injured lobule - some transitional stages of aponecrosis can be detected; presence of pycnotic nuclei (arrows); marked disintegration of the cell cytoplasm; bar $50 \mu \mathrm{m}$; All samples prepared by semithin epon section, toluidine blue. 
Oxidative stress causes an increase in production of nitric oxide, a molecule which plays a complex role in both oxidative stress and cell death responses. The activity of $\mathrm{NO}$ in this study was reflected in the measurement of its oxidation end product nitrite in plasma, which has been significantly increased in parallel with the gene expression of NOS-2 enzyme in the D-GalN/LPS group. One of the important influences of NOS-2 enzyme is that once it is induced by increased levels of TNF- $\alpha$, it produces nitric oxide that in turn stimulates additional production of TNF- $\alpha$ resulting in inflammatory injury (Sass et al. 2001). Furthermore, nitric oxide is thought to play a dual role in apoptosis acting as both pro-apoptotic and anti-apoptotic mediator depending on various cellular conditions and cell types (Chung et al. 2001, Brune 2005). Some studies have shown that this inducible isoenzyme in certain cell types contributes to cell death by increasing caspase 3 activity due to increased cytokine levels such as TNF- $\alpha$ (Obara et al. 2010). Earlier studies on hepatocytes however have shown that nitric oxide exerts anti-apoptotic action through direct inhibition of caspase activity by S-nitrosylation, resulting in prevention of Bcl-2 cleaveage and cytochrome C release (Li et al. 1997, Kim et al. 1998). Although we have not been able to observe any significant change in Caspase 3 activity in D-GalN/LPS treated animals, there was a significant increase in Casp 3 and NOS-2 gene expressions. Furthermore, some studies have shown that the induced HO-1 enzyme exerts its cytoprotective action through inhibition of inflammatory NOS-2 induction, decrease in levels of cytokines and decreased Caspase 3 activity (Sass et al., 2003, Wen et al. 2003). Therefore, the last reports support our present findings in so far as the relationship between HO-1 and billirubin from one hand and NOS-2 and Casp 3 gene expresion on the other hand.

It is well established that interdependence of members of $\mathrm{Bcl}-2$ pro-apoptotic and antiapoptotic proteins plays a major role in apoptotic cell death, through their action on mitochondrial permeability pores, cytochrome $\mathrm{C}$ release and activation of caspases (Garcia-Saez et al. 2010, Chipuk and Green 2008). The increases in measured gene expressions of Bcl-2 pro-apoptotic members, Bid and Bax, as well as that of Casp 3 gene expression signify an early initiation of the apoptotic pathways. Furthermore, the morphological evaluation of D-GalN/LPS treated rats has shown the presence of pycnotic nuclei, which in those cells support a classification of running apoptotic process. In addition, the simultaneously marked disintegration of their cytoplasm shows a necrotic continuation, apparently, following process of apoptotic cell death. Typical changes and aggregation of heterochromatin near the nuclear envelope testify an occurence of apoptosis in some hepatocytes. These findings support the concept of the presence of apoptosis which was followed by necrotic changes, in other words aponecrotic cell death.

Reduced glutathione (GSH) is a powerful antioxidant that protects cells from oxidative injury by scavenging reactive oxygen/nitrogen species and a homeostatic decrease in the GSH pool can make cells more vulnerable to further damage by toxins (Ballatori et al. 2009). In this study, the GSH levels were similar between the control and D-GalN/LPS group, indicating that the GSH pool has remained intact. In addition to antioxidant action of GSH, the antioxidant enzymes SOD1, Gpx 1 and catalase work together to counteract the oxidation of proteins, lipids and DNA, by removing ROS from the cell (Yuan and Kaplowitz 2008). Specifically, SOD reduces superoxide into hydrogen peroxide, which is further reduced to water by the action of catalase and glutathione peroxidase (Valdivia et al. 2009). It is noteworthy that within the present experimental conditions gene expression of SOD1 decreased significantly, while that of the Gpx1 remained unchanged. Catalase was significantly induced by D-GalN/LPS as was seen by significantly increased levels in plasma. It might be expected that under the present experimental conditions, the responses of these three parameters would be increased in parallel, however, under D-GalN/LPS toxicity the expected mutual relationship of these antioxidant enzymes was not seen. Differential response of these enzymes may be dependent on the dictating cellular needs in fight against increased levels of reactive oxygen species in induced oxidative stress states (Djordjevic et al. 2010).

In summary, D-GalN/LPS induced hepatotoxicity has resulted in a differential oxidative stress response as reflected by the alterations in expressions of certain oxidant/antioxidant genes, while the expression of others remained unchanged. Even though our findings were not able to confirm a direct relationship between the oxidative and apoptotic parameters that were tested, a parallel relationship between selected enzymes' gene expressions and their respective biochemical markers was seen. Thus, the real time PCR analysis of certain genes, which according to the present conditions is extremely sensitive, combined with conventional biochemical markers and morphology is potentially a very useful tool in 
understanding various steps involved in D-GalN/LPS induced fulminant hepatic injury.

\section{Conflict of Interest}

There is no conflict of interest.

\section{Acknowledgements}

This work was supported by the research grants GAČR 305/09/0004, VZ MSM 0021620807, GAČR 305/07/0061 and SVV-2010-260512.

\section{References}

AEBI H: Catalase in vitro. Methods Enzymol 105: 121-126, 1984.

AROCHO A, CHEN B, LADANYI M, PAN Q: Validation of the 2-DeltaDeltaCt calculation as an alternate method of data analysis for quantitative PCR of BCR-ABL P210 transcripts. Diagn Mol Pathol 15: 56-61, 2006.

BALLATORI N, KRANCE SM, NOTENBOOM S, SHI S, TIEU K, HAMMOND CL: Glutathione dysregulation and the etiology and progression of human diseases. Biol Chem 390: 190-214, 2009.

BARANANO DE, RAO M, FERRIS CD, SNYDER SH: Biliverdin reductase: a major physiologic cytoprotectant. Proc Natl Acad Sci USA 99: 16093-16098, 2002.

BRUNE B: The intimate relation between nitric oxide and superoxide in apoptosis and cell survival. Antioxid Redox Signal 7: 497-507, 2005.

CHAN G, TAQI A, MAROTTA P, LEVSTIK M, MCALISTER V, WALL W, QUAND D: Long-term outcomes of emergency liver transplantation for acute liver failure. Liver Transpl 15: 1696-1702, 2009.

CHUNG HT, PAE HO, CHOI BM, BILLIAR TR, KIM YM: Nitric oxide as bioregulator of apoptosis. Biochem Biophys Res Commun 282: 1075-1079, 2001.

CHIPUK JE, GREEN DR: How do BCL-2 proteins induce mitochondrial outer membrane permeabilization? Trends Cell Biol 18: 157-164, 2008.

CLARK JE, FORESTI R, GREEN CJ, MOTTERLINI R: Dynamics of heme oxygenase-1 expression and bilirubin production in cellular protection against oxidative stress. Biochem J 348: 615-619, 2000.

DIESEN DL, KUO PC: Nitric oxide and redox regulation in the liver: Part I. General considerations and redox biology in hepatitis. J Surg Res 162: 95-109, 2010.

DJORDJEVIC J, DJORDJEVIC A, ADZIC M, NICIFOROVIC A, RADOJCIC MB: Chronic stress differentially affects antioxidant enzymes and modifies the acute stress response in liver of Wistar rats. Physiol Res 59: 729$736,2010$.

FARGHALI H, CERNY D, KAMENIKOVA L, MARTINEK J, HORINEK A, KMONICKOVA E, ZIDEK Z: Resveratrol attenuates lipopolysaccharide-induced hepatitis in D-Galactosamine sensitized rats: role of nitric oxide synthase 2 and heme oxygenase-1. Nitric Oxide 21: 216-225, 2009.

FAROMBI EO, SURH YJ: Heme oxygenase-1 as a potential therapeutic target for hepatoprotection. $J$ Biochem $\mathrm{Mol}$ Biol 39: 479-491, 2006.

FENG B, WU S, LV S, LIU F, CHEN H, YAN X, LI Y, DONG F, WEI L: Metabolic profiling analysis of a Dgalactosamine/lipopolysaccharide-induced mouse model of fulminant hepatic failure. J Proteome Res 6: 21612167, 2007.

GARCIA-SAEZ AJ, FUERTES G, SUCKALE J, SALDAGO J: Permeabilization of the outer mitochondrial membrane by Bcl-2 proteins. Adv Exp Med Biol 677: 91-105, 2010.

GATZIDOU ET, ZIRA AN, THEOCHARIS SE: Toxicogenomics: a pivotal piece in the puzzle of toxicological research. J Appl Toxicol 27: 302-309, 2007.

HARRIL AH, RUSYN I: Systems biology and functional genomics approaches for the identification of cellular responses to drug toxicity. Expert Opin Drug Metab Toxicol 4: 1379-1389, 2008.

HONG JY, LEBOFSKY M, FARHOOD A, JAESCHKE H: Oxidant stress-induced liver injury in vivo: role of apoptosis, oncotic necrosis, and c-Jun NH2-terminal kinase activation. Am J Physiol Gastrointest Liver Physiol 296: G572-G581, 2009.

KIM YM, KIM TH, SEOL DW, TALANIAN RV, BILLIAR TR: Nitric oxide suppression of apoptosis occurs in association with an inhibition of Bcl-2 cleavage and cytochrome C release. J Biol Chem 273: 31437-31441, 1998. 
LEHMANN E, EL-TANTAWY WH, OCKER M, BARTENSCHLAGER R, LOHMANN V, HASHEMOLHOSSEINI S, TIEGS G, SASS G: The heme oxygenase-1 product biliverdin interferes with hepatitis $\mathrm{C}$ virus replication by increasing antiviral interferon response. Hepatology 51: 398-404, 2010.

LI J, BILLIAR TR, TALANIAN RV, KIM YM: Nitric oxide reversibly inhibits seven members of the caspase family via S-nitrosylation. Biochem Biophys Res Commun 240: 419-424, 1997.

LICHTMAN SN, WANG J, SCHWAB JH, LEMASTERS JJ: Comparison of peptidoglycan-polysaccharide \& lipopolysaccharide stimulation of Kupffer cells to produce tumor necrosis factor and interleukin-1. Hepatology 19: 1013-1022, 1994.

LIU LM, ZHANG JX, LUO J, GUO HX, DENG H, CHEN JY, SUN SL: A role of cell apoptosis in lipopolysaccharide (LPS)-induced nonlethal liver injury in D-galactosamine (D-GalN)-sensitized rats. Dig Dis Sci 53: 1316-1324, 2008.

MARI M, MORALES A, COLELL A, GARCIA-RUIZ C, FRNANDES-CHECA JC: Mitochondrial glutathione, a key survival antioxidant. Antioxid Redox Signal 11: 2685-2700, 2009.

MORGAN MJ, LIU ZG: Reactive oxygen species in TNF alpha-induced signaling and cell death. Mol Cells 1: 1-12, 2010.

OBARA H, HARASAWA R: Nitric oxide causes anoikis through attenuation of E-cadherin and activation of caspase-3 in human gastric carcinoma AZ-521 cells infected with Mycoplasma hyorhinis. J Vet Med Sci 72: 869-874, 2010.

OBERHOLZER A, OBERHOLZER C, BAHJAT FR, EDWARDS CK 3RD, MOLDAWER LL: Genetic determinants of lipopolysaccharide and D-galactosamine-mediated hepatocellular apoptosis and lethality. $J$ Endotoxin Res 7 : 375-380, 2001.

SASS G, KOERBER K, BANG R, GUEHRING H, TIEGS G: Inducible nitric oxide synthase is critical for immunemediated liver injury in mice. J Clin Invest 107: 439-447, 2001.

SASS G, SOARES MC, YAMASHITA K, SEYFRIED S, ZIMMERMANN WH, ESCHENHAGEN T, KACZMAREK E, RITTER T, VOLK HD, TIEGS G: Heme oxygenase-1 and its reaction product, carbon monoxide, prevent inflammation-related apoptotic liver damage in mice. Hepatology 38: 909-918, 2003.

SASS G, SEYFRIED S, PARREIRA SM YMASHITA K, KACZMAREK E, NEUHUBER WL, TIEGS G: Cooperative effect of biliverdin and carbon monoxide on survival of mice in immune-mediated liver injury. Hepatology 40: 1128-1135, 2004.

SEDLAK J, LINDSAY RH: Estimation of total protein-bound and nonprotein sulfhydryl groups in tissue with Ellmans reagent. Anal Biochem 25: 192-205, 1968.

SILVERSTEIN R: D-galactosamine lethality model: scope and limitations. J Endotoxin Res 10: 147-162, 2004.

STACHLEWITZ RF, SEABRA V, BRADFORD B, BRADHAM CA, RUSYN I, GERMOLEC D, THURMAN RG: Glycine and uridine prevent D-galactosamine hepatotoxicity in the rat: role of Kupffer cells. Hepatology 29: 737-745, 1999.

VALDIVIA A, PEREZ-ALVAREZ S, AROCA-AGUILAR JD, IKUTA I, JORDAN J: Superoxide dismutases: a physiopharmacological update. J Physiol Biochem 65: 195-208, 2009.

VAN HERREWEGHE F, FESTJENS N, DECLERCQ W, VANDENABEELE P: Tumor necrosis factor-mediated cell death: to break or to burst, that's the question. Cell Mol Life Sci 67: 1567-1579, 2010.

WEN T, WU ZM, LIU Y, TAN YF, REN F, WU H: Upregulation of heme oxygenase-1 with hemin prevents Dgalactosamine and lipopolysaccharide-induced acute hepatic injury in rats. Toxicology 237: 184-193, 2007.

YOKODE M, KITA T, KIKAWA Y: Stimulated arachidonate metabolism during foam cell transformation of mouse peritoneal macrophages with oxidized low density lipoprotein. J Clin Invest 76: 720-729, 1988.

YUAN L, KAPLOWITZ N: Glutathione in liver diseases and hepatotoxicity. Mol Aspects Med 30: 29-41, 2008.

ZHU Z, WILSON AT, MATHAHS MM, WEN F, BROWN KE, LUXON BA, SCHMIDT WN: Heme oxygenase-1 suppresses hepatitis $\mathrm{C}$ virus replication and increases resistance of hepatocytes to oxidant injury. Hepatology 48: 1430-1439, 2008. 